\title{
Ascaris lumbricoides
}

National Cancer Institute

\section{Source}

National Cancer Institute. Ascaris lumbricoides. NCI Thesaurus. Code C122177.

A genus of parasitic nematode in the family Ascarididae. A. lumbricoides is the largest

intestinal roundworm infecting humans and is the causative agent of ascariasis. 